\title{
SURFACE ENERGY BALANCE OVER ORANGE ORCHARD USING SURFACE RENEWAL ANALYSIS
}

\author{
Salvatore Barbagallo, Simona Consoli, Alfonso Russo
}

\section{Introduction}

Evapotranspiration (ET) rates can be estimated by micrometeorological methods and the energy balance equation, soil depletion techniques, mass exchange methods, or by using weighting lysimeters. These methods usually are expensive, difficult to operate, and some of them present problems for measurements in heterogeneous vegetation [Simmons 2007]. Therefore, the search for accurate methods for estimating ET fluxes using low-cost, transportable and robust instrumentations is a subject of interest [Castellvì 2008]. While the preferred method for measuring turbulent fluxes (sensible heat, latent heat, carbon dioxide, etc...) is the eddy covariance (EC) method, the lack of closure is unresolved (commonly attributed to the lack of fetch and loss of flux by convection) and a full guidance on experimental set up and raw data processing is still unavailable [Mauder 2007]. In addition, the EC method is not always affordable, and the high cost may limit the number of desired measurements in a given study. Other energy balance approaches, such as the Bowen ratio and aerodynamic methods, have a sound theoretical basis and can be highly accurate for some surfaces under acceptable conditions. Surface Renewal (SR) theory [Paw U 1991] in conjunction with the analysis of the observed ramp-like patterns in the scalar traces provides an advantageous method for estimating the surface flux density of a scalar. A detailed review of SR analysis is given by Paw U (2005) and the performance of SR over a variety of canopies are shown in Castellvì (2004), Consoli (2006) and Castellvì (2008). Results of the studies have demonstrated good SR perform-

Paper received 16.06.2009; accepted 10.09.2009

S. Barbagallo, Full professor, Dipartimento di Ingegneria Agraria, University of Catania, Via S. Sofia, 100 - 95123 Catania (Italy); S. Consoli, Researcher, Dipartimento di Ingegneria Agraria, University of Catania, Via S. Sofia, 100 - 95123 Catania (Italy); simona.consoli@ unict.it corresponding author; A. Russo, PhD, Dipartimento di Ingegneria Agraria, University of Catania, Via S. Sofia, 100 - 95123 Catania (Italy). ance in terms of flux densities estimation, well correlated with EC measurements.

This paper evaluates the performance of SR analysis of sensible heat flux $(\mathrm{H})$ data collected over an orange orchard in Sicily during a four-years period (2005-2008). SR estimates of $\mathrm{H}$ were used to solve the surface energy balance of the investigated soilplant-atmosphere continuum and, thus, to determine ET fluxes and crop coefficient $\left(\mathrm{K}_{c}\right)$ data.

\section{Materials and methods}

\subsection{The site and climatic features}

The experimental site consists of approximately $3.5 \mathrm{~m}$ tall orange orchard (Tarocco cultivar) located in the north-east part of Catania (Eastern Sicily). In the orchard (about $6 \mathrm{ha}$ ), the trees were planted at a distance of $5.0 \mathrm{~m}$ in the row and $5.0 \mathrm{~m}$ between rows, with a density of 400 trees per hectare. The trees were 20 years old with about $70 \%$ of the ground shaded. Crops planting area is large enough to provide adequate fetch length for SR measurement. The least fetch length is around $100 \mathrm{~m}$.

Irrigation applications are supplied by the SalsoSimeto river system, delivered from collective water distribution networks at fixed intervals and applied at farm level by micro-sprayers. Maximum temperatures during the irrigation season (May-September) were higher than $35^{\circ} \mathrm{C}$ and minimum temperatures never dropped below $7^{\circ} \mathrm{C}$. The warm (relative humidity of about $80 \%$ ) summer was characterized by an high dew point temperature, with a maximum of $19^{\circ} \mathrm{C}$ at the end of July. Solar radiation has an average value of $23 \mathrm{MJ} \mathrm{m}^{-2} \mathrm{~d}^{-1}$ with a maximum of $31 \mathrm{MJ} \mathrm{m}^{-2} \mathrm{~d}^{-1}$. The average cumulated yearly rainfall is around 550 $\mathrm{mm}$ and never increased above $100 \mathrm{~mm}$ during MayAugust period. The time variation of the discussed whether data (including solar radiation, air temperature, vapour pressure, relative humidity, wind speed and direction, and rainfall) came from an automatic weather station (Campbell Scientific, Logan, UT) located about $5 \mathrm{~km}$ away from the experimental field 
and placed in a small field of grass. Hourly weather data were used to calculate reference evapotranspiration $\mathrm{ET}_{0}$ using the FAO 56 Penman-Monteith equation for short crops [Allen 1998]. Soil texture at the experimental field was $50.7 \%, 13.2 \%$ and $36.1 \%$ of sand, silt and clay, respectively, and the soil bulk density was $1.41( \pm 0.17) \mathrm{g} \mathrm{cm}^{-3}$. The maximum soil moisture value, measured by TDR sensors, in the upper $0.6 \mathrm{~m}$ was $0.40 \mathrm{~m}^{3} \mathrm{~m}^{-3}$, the minimum soil moisture had dropped to $0.15 \mathrm{~m}^{3} \mathrm{~m}^{-3}$. Leaf area index (LAI) values were measured with a Licor LAI-2000 digital analyzer at regular intervals during the monitoring. PAR light interception by the studied crops was also investigated by line quantum sensors.

\subsection{Micrometeorological fluxes monitoring}

A Surface Renewal-Energy Balance (SREB) micrometeorological tower was installed in the experimental orchard during July $7^{\text {th }} 2005$ (Figure 1). In the long-term energy fluxes monitoring program, data registered from July 2005 to September 2008 were analysed. The SR system consisted of two fine wire thermocouples (76.2 $\mu \mathrm{m}$ of thickness) installed $0.5 \mathrm{~m}$ above the canopy top. Air temperature was monitored with the thermocouples at $4 \mathrm{~Hz}$ frequency.

Following Paw U (1991), traces of high-frequency temperature data show ramp-like structures. The coherent structure theory assumes that an air parcel sweeps from above to the surface. The transfer between the air and the canopy elements lead to heating or cooling of the air while is at the surface (Figure 2). Two parameters characterize these mean temperature ramps for stable and unstable atmospheric conditions: the amplitude (a) and the inverse ramp frequency $(1+s)$. The mean values of these two parameters during a time interval can be used to estimate $\mathrm{H}$ (Eq. 1) over the monitored crop canopy using $\mathrm{SR}$ analysis. Sensible heat flux $\left(\mathrm{H}, \mathrm{W} \mathrm{m}^{-2}\right)$ is the energy used to heat the air or energy gained by cooling the air.

$$
\mathrm{H}=\alpha \rho \mathrm{c} p \frac{\mathrm{a}}{1+\mathrm{s}} \mathrm{z}
$$

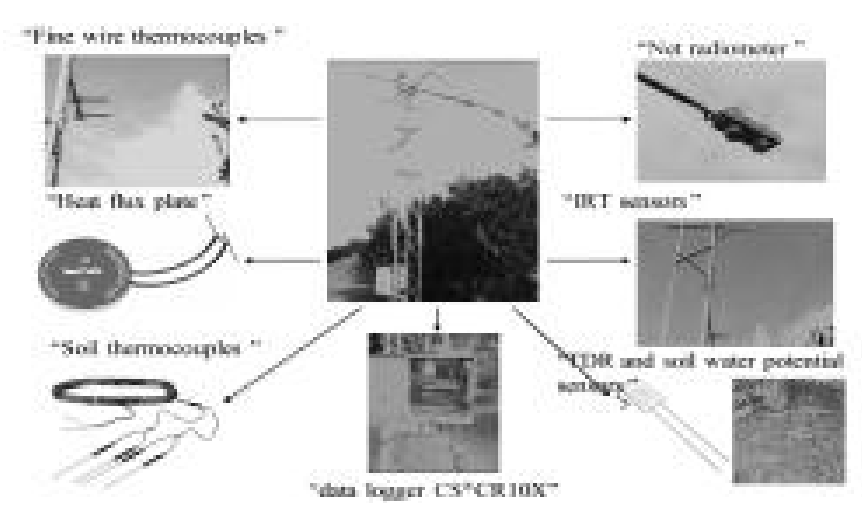

Fig. 1 - SREB tower at the experimental field.

$$
S^{P}(r)=\frac{1}{m-j} \sum_{i=1+j}^{m}\left[r_{i}-T_{i-j}\right]
$$

where $\alpha$ is a weighting factor accounts for the spatially averaged (vertical) air temperature from the bottom to the top of the air parcel; $\rho$ is the air density, $c_{p}$ is specific heat of air; $\mathrm{z}$ is the sensor measurement height.

Several solutions have been proposed to estimate the mean ramp characteristics and Snyder (1996), Spano (1997) suggested the Van Atta approach. Following Van Atta (1977), high-frequency temperature measurements are used to determine structure functions $\mathrm{SP}(\mathrm{r})$ (Eq. 2), where $\mathrm{m}$ is the number of data points measured at a frequency $\mathrm{f}(\mathrm{in} \mathrm{Hz})$ within a $\mathrm{t}$ minute interval, $p$ is the power function $(p=2,3$ and $5), \mathrm{j}$ is a sample lag between data points corresponding to a time lag $\mathrm{r}=\mathrm{i} / \mathrm{j}$, and $\mathrm{T}_{\mathrm{i}}$ is the $\mathrm{i}$-th temperature sample. The mean amplitude (a) for the t-minute interval is estimated by solving Eq. 3 for the real roots:

$$
\begin{gathered}
a^{3}+\left[10 s^{2}(r)-\frac{s^{5}(r)}{s^{3}(r)}\right] a+10 s^{3}(r)=0 \\
1+s=-\frac{a^{3}(r)}{s^{3}(r)}
\end{gathered}
$$

Finally, the inverse ramp frequency $(1+s)$ is calculated by the Eq. 4 .

The energy balance equation (Eq. 5) was solved to obtain latent heat flux (LE, energy used for evaporation or gained from condensation) values using measured net radiation and soil heat flux, and estimated $\mathrm{H}$ from SR analysis during 2005-2008 monitoring period.

$$
\begin{gathered}
\mathrm{LE}=\mathrm{R} N-\mathrm{G}-\mathrm{H} \\
\Delta \mathrm{S}=\mathrm{C}_{\mathrm{v}} \frac{\partial \mathrm{T}}{\partial \mathrm{t}} \delta \mathrm{z}
\end{gathered}
$$

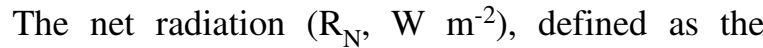
amount of radiant energy that is available to be partitioned into the other forms of surface energy, was

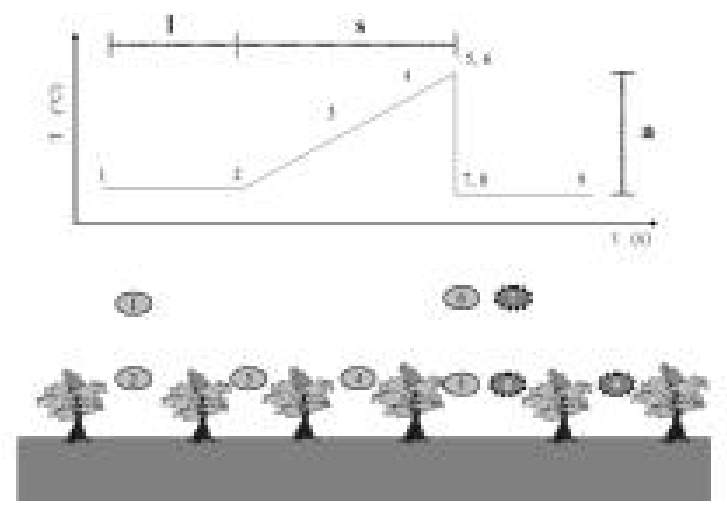

Fig. 2 - Air temperature traces as ramp-like characteristics. 
measured using a net radiometer (Kipp and Zonen) placed at $1.5 \mathrm{~m}$ height above the canopy top. Soil or

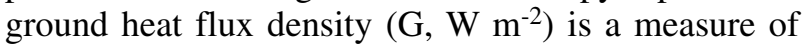
how much energy is conducted upward or downward from or into the soil surface; it can be difficult to measure, and accuracy is important. The soil heat flux was measured as the mean output of three soil heat flux plates (model HFP-01, Hukseflux Thermal Sensors). They were buried $0.05 \mathrm{~m}$ below the surface. The gradual build up of plant matter changed the thermal properties of the upper layers. Consequently, heat storage $(\Delta S)$ was quantified in the upper layer by measuring the time rate of change in temperature [Fuchs 1967]. Three probes (TCAV) were placed in the soil to sample soil temperature. The sensors were placed 0.01-0.04 m (z) below the surface (in Eq. 6); $\mathrm{C}_{\mathrm{v}}$ is the volumetric heat capacity of the soil and can be estimated from the volumetric fractions of minerals $\left(\mathrm{V}_{\mathrm{m}}\right)$, organic matter $\left(\mathrm{V}_{0}\right)$ and volumetric water content $(\theta)$. Therefore, $G$ at the surface is estimated by measuring $G^{\prime}$ at the depth of $0.05 \mathrm{~m}$ and the change in temperature with time of the soil layer above the heat flux plates to determine $\Delta S$.

Finally, to convert the latent heat flux (LE) into actual water mass flux $\left(\mathrm{ET}_{\mathrm{a}}\right), \mathrm{LE}$ was divided by the latent heat of vaporization ( $\lambda \mathrm{E}$ ) equal to $2.45\left[\mathrm{MJ} \mathrm{kg}^{-1}\right]$. Estimates of crop coefficient $\mathrm{K}_{\mathrm{c}}$, obtained as ration between $\mathrm{ET}_{\mathrm{a}}$ (assuming $\mathrm{ET}_{\mathrm{a}}=\mathrm{ET}_{\mathrm{c}}$ due to well watered conditions) and reference ET (ET ${ }_{0}$, were compared with $\mathrm{K}_{\mathrm{c}}$ data from $\mathrm{FAO}$ papers.

Sensible heat flux data from SR technique $\left(\mathrm{H}_{\mathrm{SR}}\right)$ were calibrated with independent measurements of $\mathrm{H}_{\mathrm{EC}}$ by a 3-D sonic anemometer (Gill Wind-Master) located in the same area of study. The calibration data subset was used to derive the $\alpha$ value of Eq. 1 by simple linear regression forced through the origin. For this regression, $\mathrm{H}_{\mathrm{EC}}$ was used as the dependent variable and $\mathrm{H}_{\mathrm{SR}}$ as the independent one. In this way, the regression slope was the $\alpha$ value looked for, used to correct $\mathrm{H}$ from the uncalibrated $\mathrm{SR}$ analysis.

\section{Results and discussion}

Table 1 shows the mean values for surface fluxes corresponding to four different datasets during the monitoring periods. Two datasets were formed from samples gathered under unstable and stable surfacelayer atmospheric conditions. In particular, stablecase data set corresponded to night time periods with negative $\mathrm{R}_{\mathrm{N}}-\mathrm{G}$ (available energy) and small $\mathrm{H}$ and LE. The unstable data set is referred to diurnal periods where $R_{N}-G$ is positive, with the exception of the periods close to sunrise, sunset and late afternoon that may be included in the stable-case data set. The dry and humid period data sets correspond, for the area under study, to May-September and October-April, respectively. As shown in Table 1, the energy partitioning of the available net surface energy was remarkably distinct for these different datasets. During both dry and humid periods well-formed ramp traces of air temperature were observed, which explains the good performance of LE values. Under unstable atmospheric conditions, when a cool air parcel moves instantaneously downward and travels horizontally (see Figure 2), a positive amplitude ramp (a) in the temperature trace is observed (positive $\mathrm{H}$ ). For this reason, in the unstable-case when $R_{N}-G$ is positive, most of the available net surface energy contribute to positive latent heat flux. It reached a maximum of around $650 \mathrm{~W} \mathrm{~m}^{-2}$ during late July of the monitoring periods. The average hourly ratio H/LE during dry pe-

\begin{tabular}{|c|c|c|c|c|c|}
\hline Year & \multicolumn{2}{|c|}{ atmospheric condition } & $\begin{array}{c}\mathrm{H}_{\mathrm{SR}} \\
\left(\mathrm{W} \mathrm{m}^{-2}\right)\end{array}$ & $\begin{array}{c}\mathrm{LE} \\
\left(\mathrm{W} \mathrm{m}^{-2}\right)\end{array}$ & $\begin{array}{c}\mathrm{R}_{\mathrm{N}}-\mathrm{G} \\
\left(\mathrm{W} \mathrm{m}^{-2}\right)\end{array}$ \\
\hline \multirow{4}{*}{2005} & \multirow{2}{*}{ unstable } & dry period & 77.4 & 255.8 & 331.6 \\
\hline & & humid period & 27.9 & 116.1 & 143.8 \\
\hline & \multirow{2}{*}{ stable } & dry period & -11.9 & -32.6 & -45.2 \\
\hline & & humid period & -18.7 & -23.7 & -42.0 \\
\hline \multirow{4}{*}{2006} & \multirow{2}{*}{ unstable } & dry period & 34.9 & 283.5 & 320.3 \\
\hline & & humid period & 35.2 & 140.0 & 176.9 \\
\hline & \multirow{2}{*}{ stable } & dry period & -4.6 & -29.4 & -35.9 \\
\hline & & humid period & -10.5 & -28.5 & -39.6 \\
\hline \multirow{4}{*}{2007} & \multirow{2}{*}{ unstable } & dry period & 34.6 & 262.9 & 299.6 \\
\hline & & humid period & 19.4 & 157.0 & 177.8 \\
\hline & \multirow{2}{*}{ stable } & dry period & -4.4 & -30.2 & -36.5 \\
\hline & & humid period & -6.4 & -28.6 & -36.0 \\
\hline \multirow{4}{*}{2008} & \multirow{2}{*}{ unstable } & dry period & 77.5 & 146.0 & 223.6 \\
\hline & & humid period & 42.6 & 108.5 & 151.0 \\
\hline & \multirow{2}{*}{ stable } & dry period & -4.9 & -29.7 & -36.9 \\
\hline & & humid period & -8.8 & -24.7 & -33.9 \\
\hline
\end{tabular}

TABLE 1 - Mean values of energy fluxes during unstable and stable conditions. 
riods was around 0.56 and reached the peak between 12.00 a.m. and 2.00 p.m. Under stable atmospheric conditions, the temperature, generally, risen as the warm air swept into the canopy an heat transferred from the air to the plant canopy elements, causing a slow temperature drop $(\mathrm{a}<0$ and $\mathrm{H}<0)$.

In the study, the latent heat flux, the energy transfer due to evaporation or condensation, was largely dependent on leaf area index (LAI) and PAR light interception (LI) by vegetation, with peaks when LAI and PAR LI were higher.

The hourly patterns of energy fluxes in the orchard is presented for the same days-period in Figure 3. In all the years the energy balance calculations were fairly similar.

On the average, the evaporative fraction $\mathrm{EF}(\%)$, the ration between LE and the available surface energy $\left(\mathrm{R}_{\mathrm{N}}-\mathrm{G}\right)$ was of about $80 \%$, during the dry period and under unstable-case atmospheric conditions.

The regression of half hourly averages of sensible heat flux density $\left(\mathrm{H}_{\mathrm{EC}}\right)$ from a sonic anemometer versus uncalibrated Surface Renewal measurements of $\mathrm{H}$ was carried out during the months of July of the years 2005 and 2006. The slope of the regression of $\mathrm{H}_{\mathrm{EC}}$ versus uncalibrated $\mathrm{H}_{\mathrm{SR}}$ was of about 0.24 with a determination coefficient $\mathrm{R}^{2}=0.85$. This calibration for $\alpha$ (Eq. 1) was used during 2007 and 2008.

Since daily variation of energy balance components during the 4-years of monitoring shows more or less same trend, four observation periods of the dry seasons were taken to depict the daily variation of surface energy fluxes (Figure 4). During summer, LE values had an average of about $11.0 \mathrm{MJ} \mathrm{m}^{-2} \mathrm{~d}^{-1}$ and a maximum of $17.4 \mathrm{MJ} \mathrm{m}^{-2} \mathrm{~d}^{-1}$, with a variation of about 0.5 . Study revealed that net radiation $\left(R_{N}\right)$ was highest at 12.00 noon, with the daily mean value of about $13.2 \mathrm{MJ} \mathrm{m}^{-2} \mathrm{~d}^{-1}$, maximum around $18.0 \mathrm{MJ} \mathrm{m}^{-2}$ $\mathrm{d}^{-1}$ and variation coefficient of 0.55 . The course of soil heat flux $(\mathrm{G})$ was affected by the development of crop canopy or leaf area index. On a daily basis, $G$ density is generally close to zero. Sensible heat flux (H) had mean and maximum values of about $2.2 \mathrm{MJ}$ $\mathrm{m}^{-2} \mathrm{~d}^{-1}$ and $4.7 \mathrm{MJ} \mathrm{m}^{-2} \mathrm{~d}^{-1}$, respectively; daily $\mathrm{H}$ values resulted fairly scattered around the mean, with a variation of about 0.8 .

In general, mean reference evapotranspiration $\mathrm{ET}_{0}$ during dry periods tends to be between $5-6 \mathrm{~mm} \mathrm{~d}^{-1}$ in each year; ET $_{0}$ varied between a maximum of about $11 \mathrm{~mm} \mathrm{~d}^{-1}$ to a minimum of about $1.5 \mathrm{~mm} \mathrm{~d}^{-1}$. The mean $\mathrm{ET}_{\mathrm{a}}$ was about 4.5 (variation less than 10\%) during the dry periods of the monitoring years (Figure 5 ). Before the experiment in 2005, the orchard was topped and pruned, which probably explains the slightly lower ET $\mathrm{E}_{\mathrm{a}}$ during that season. During humid periods, mean $\mathrm{ET}_{0}$ and $\mathrm{ET}_{\mathrm{a}}$ were of about 2.3 and 1.8 $\mathrm{mm} \mathrm{d}^{-1}$, respectively.

Crop coefficient $\left(\mathrm{K}_{\mathrm{c}}\right)$ values were higher (Figure 6) than typical reported [Doorenboos 1977; Castel
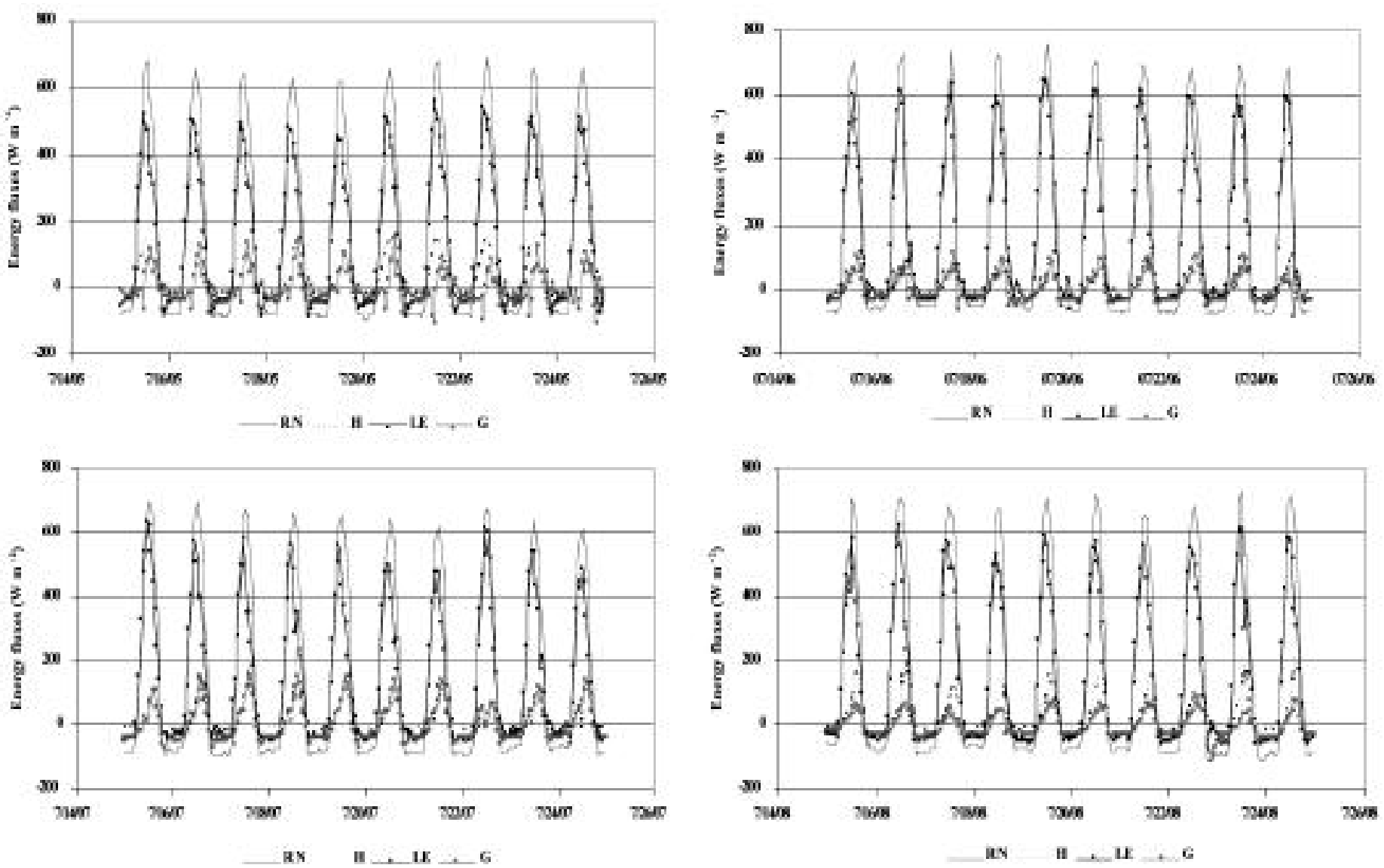

Fig. 3 - Hourly patters of energy fluxes in the orchard for a 10-days period during the monitoring years. 

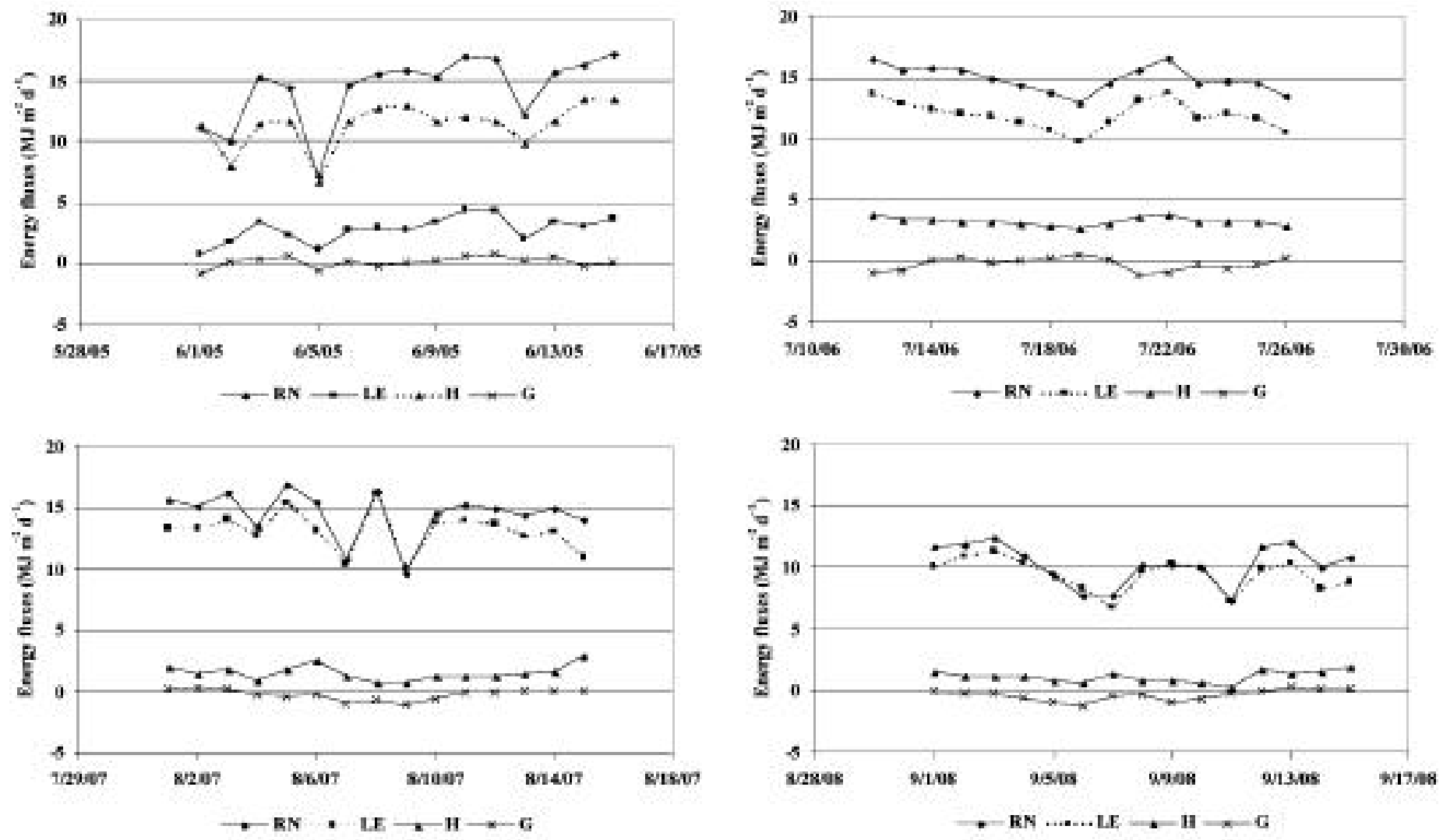

Fig. 4 - Daily variation of surface energy balance of the orange orchard at different time periods during the monitoring.
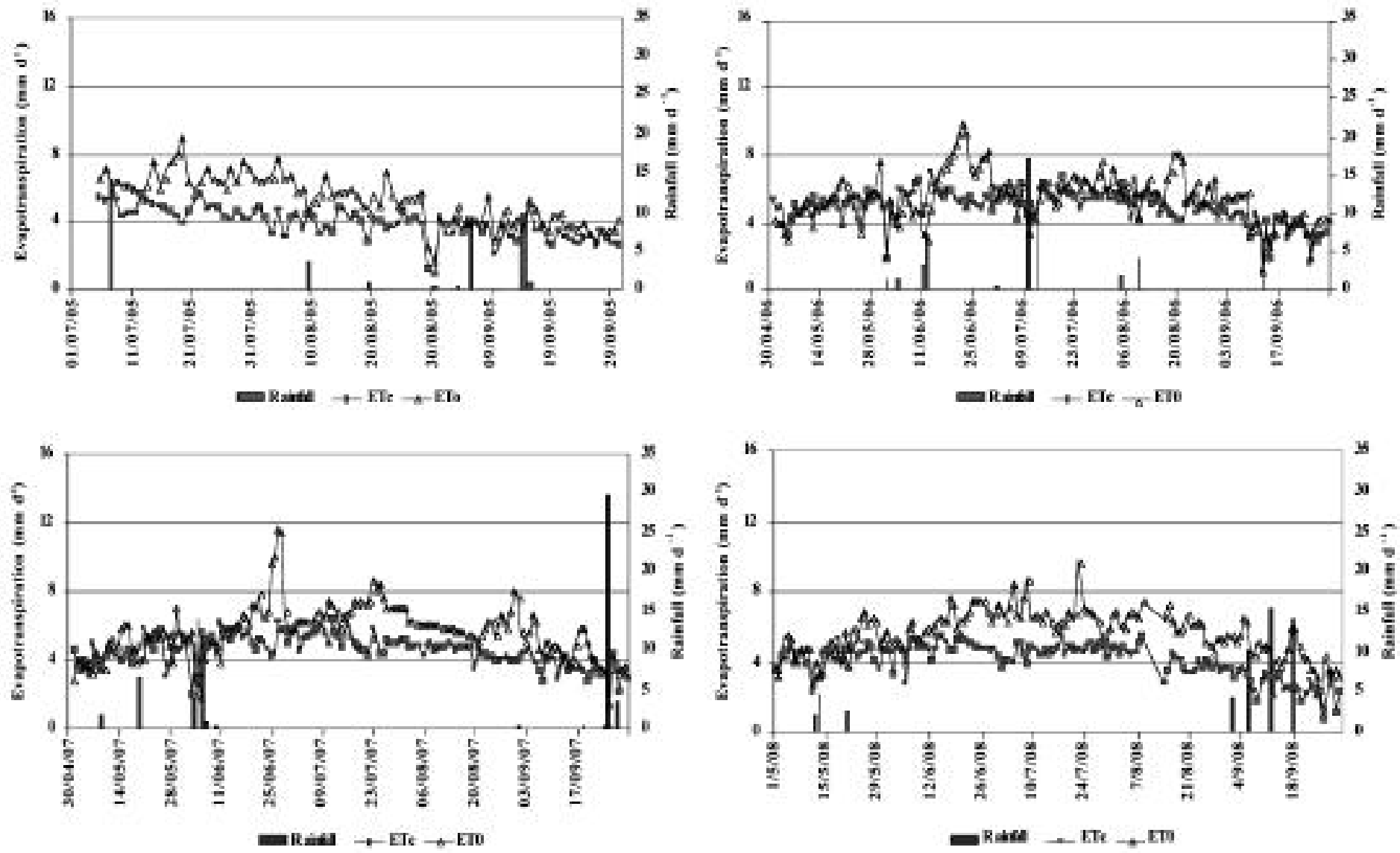

Fig. 5 - Daily rainfall and reference and crop evapotranspiration during 2005-2008 monitoring period. 
1987; Allen 1998]. The $K_{c}$ values generally increased during the monitored dry periods with averages of $0.76,0.89,0.86$ and 0.73 going from 2005 to 2008. In 2005 , the increase in summer was due to the canopy growth following topping and pruning. In 2008, the experimental orchard was less vigorous than in the previous years due to a pathogenic diseases caused by the Closterovirus Citrus Tristeza Virus (CTV). It determined significant economical income reductions for the grower. The main symptoms of the disease involve: branches desiccation, defoliation, vegetation development reduction and gradual decay of the plant until death. In particular, fruits are numerous, very small, deformed, unripe and yellow coloured. The virus mainly affects the plant root system and its water supplying capacity; others evident effects concern the reduction of vegetation indicators such as LAI, WDVI, NDVI and PAR light interception by the monitored orchards.

The rows at the experimental orchard are east-west oriented rather than north-south and this might partially explain the higher crop coefficient values. Another possible reason for the higher $\mathrm{K}_{\mathrm{c}}$ values observed in this experiment is the use of micro-sprayer irrigation rather than surface irrigation and higher application frequency in this orchard than reported in old experiments [Doorenbos 1977; Allen 1998]. In fact, these publications do not site the original source of information, and it is likely that the values came from research on flood or furrow irrigated citrus orchards prior to 1977 , so those data may be too low for dense canopy, vigorous, sprayer-irrigated orchards.

In the experimental orchard, mean $\mathrm{K}_{\mathrm{c}}$ values varied from about 0.83 to 0.74 from June to September of the monitored years. In the widely used FAO papers (27 and 56), the estimated crop coefficient for cleancultivated, mature ( $>70 \%$ cover) citrus is given as $\mathrm{K}_{\mathrm{c}}=0.65$ for June through August.

Nearly linear relationships between $K_{c}$ value and LAI and PAR light interception were observed in the study. In particular, the mean $\mathrm{K}_{\mathrm{c}}$ values during June-

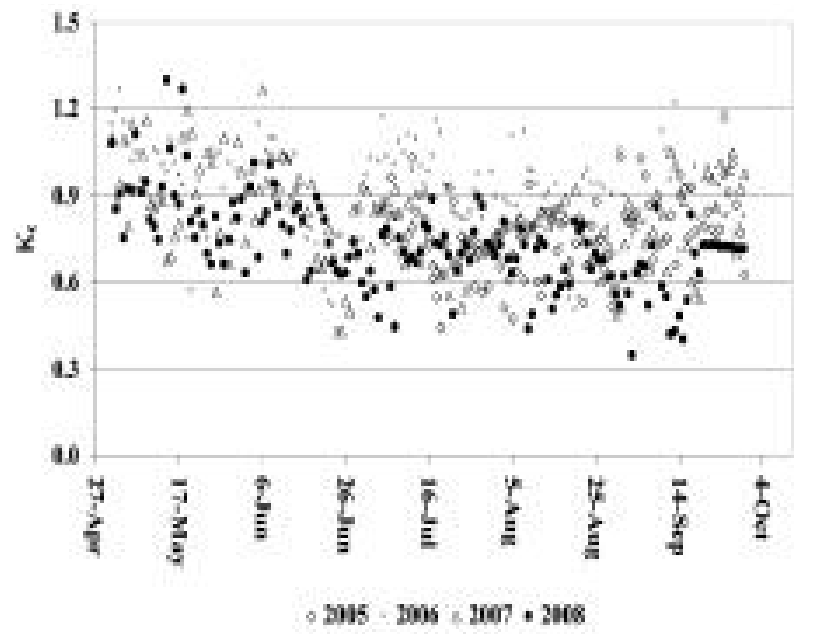

Fig. 6 - Daily $\mathrm{K}_{\mathrm{c}}$ values during 2005-2008 study periods.
September of the monitored periods were plotted versus corresponding Leaf Area Index (LAI) and PAR Light Interception (Figure 7). The peak $\mathrm{K}_{\mathrm{c}}$ value occurred at LAI of $1.8 \mathrm{~m}^{2} \mathrm{~m}^{-2}$ and PAR light interception of $80 \%$.

\section{Conclusion}

The paper reports on an experiment to evaluate surface energy fluxes using Surface Renewal (SR) analysis. Data were collected over orange orchards and analyzed for different ranges available energy, sensible and latent heat fluxes during the monitoring period 2005-2008 in eastern Sicily (Italy).

During unstable atmospheric conditions, the surface energy balance analysis revealed hourly sensible heat fluxes similar to soil heat flux data, with a mean partitioning of available energy into latent heat flux of about $80 \%$.

The crop coefficient $\left(\mathrm{K}_{\mathrm{c}}\right)$ shows apparent correspondence with the development of canopy cover, LAI and PAR Light interception. The established relationships can be useful for development algorithm of crop simulation model for predicting LAI or PAR LI. Crop coefficient values estimated from the field experiment during 2005-2008 monitoring periods were quite different (means between 0.73 and 0.89 ) from the crop coefficients published by FAO (0.65) for citrus with ground cover by vegetation of about $70 \%$. Differences between observed $\mathrm{K}_{\mathrm{c}}$ and old $\mathrm{K}_{\mathrm{c}}$ values from FAO papers are most likely due to differences in plant density, cultural practices, irrigation methods (micro irrigation techniques versus surface irrigation) and frequencies and methods to estimate references ET rates.

To conclude, measurements of high frequency temperature data for the case study showed that the structure function approach used in Surface Renewal analysis provides a good performance in terms of both $\mathrm{H}$ and LE. Fairly high correlation were found between calibrated Surface Renewal $\mathrm{H}_{\mathrm{SR}}$ and Eddy Covariance

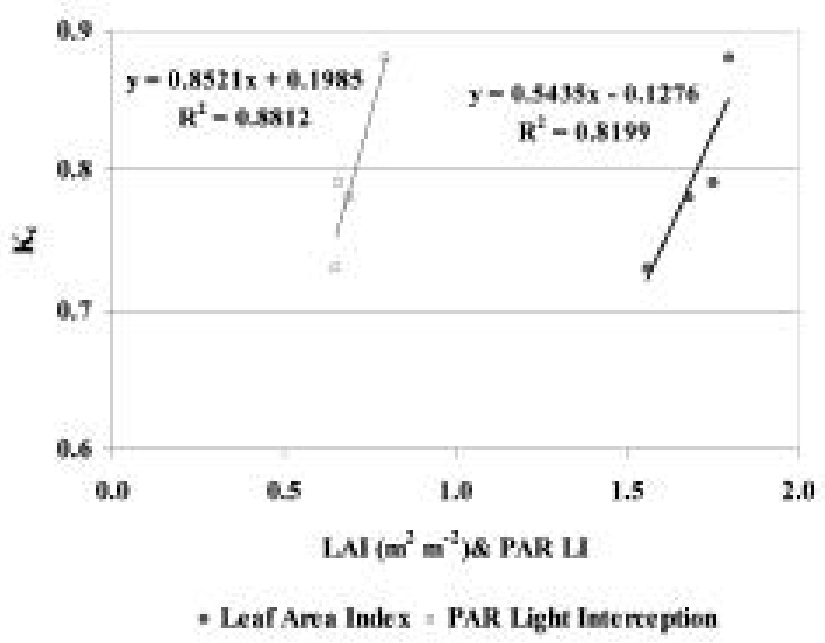

Fig. 7 - Mean $\mathrm{K}_{\mathrm{c}}$ versus LAI and PAR LI during June-September. 
$\mathrm{H}_{\mathrm{EC}}$ (from sonic anemometer). By working at $4 \mathrm{~Hz}$, Surface Renewal uses a smaller amount of data than Eddy Covariance $(10 \mathrm{~Hz})$ and allows an easier and cheap computation of sensible heat fluxes.

\section{Acknowledgments} fort.

The authors contributed to the study with equal ef-

\section{References}

Allen R.G., Pereira L.S., Raes D., Smith M. Crop evapotranspiration: Guidelines for computing crop water requirements. Irr \& Drain Paper 56 FAO, 1998, Rome.

Castel J.R., Bautista I., Ramos C., Cruz G. Evapotranspiration and irrigation efficiency of mature orange orchards in Valencia (Spain). Irrig Drain Syst, 1987 3, 205-217.

Castellvì F. 2004. Combining surface renewal analysis and similarity theory: a new approach for estimating sensible heat flux. Water Resour Res, 2004, 40, 267-278.

Castellvì F., Snyder R.L., Baldocchi D.D. Surface energybalance closure over rangeland grass using the eddy covariance method and surface renewal analysis. Agr For Meteorol, 2008, 148, 1147-1160.

Consoli S., O'Connell N.V., Snyder R.L. Estimation of evapotranspiration of different orange sized orchard canopies using energy balance. J of Irr and Drain Eng, ASCE, 2006, 32(1), 2-8.

Doorenbos J., Pruitt W.O. Crop water requirements. Irr \& Drain Paper 24 FAO, 1977, Rome.

Fuchs M., Tanner C.B. Evaporation from drying soil. J. Appl. Meteorol, 1967, 6, 852-857.

Mauder M., Oncley S.P., Vogt R., Weidinger T., Ribiero L., Bernhofer C., Foken T., Koisek W., De Bruin H., Liu H. The energy balance experiment EBEX-2000. Part II: Intercomparison of eddy covariance sensors and post-field data processing methods. Bound. Layer Meteorol, 2007, 123, 29-54.

Paw U.K.T., Brunet Y. A Surface Renewal measure of Sensible Heat Flux Density. Proceedings of 20th Conference on Agriculture and Forest Meteorology, Sept. 10-13, 1991, Salt Lake City, Utah. American Meteorology Society, Boston, MA, 1991, 52-53.

Paw U.K.T., Snyder R.L., Spano D., Su H.B. Surface renewal estimates of scalar exchanges, Micrometeorology in Agricultural Systems, Agronomy Monograph 47, Chapter 20, 2005, ASA-CSSA-SSSA Publisher, Madison (WI, USA).
Simmons L.J., Wang J., Sammis T.W., Miller D.R. An evaluation of two inexpensive energy-balance techniques for measuring water use in flood-irrigated pecans (Carya illinoinensis). Agricultural Water Management, 2007, 88, 181-191.

Snyder R.L., Spano D., Paw U.K.T. Surface Renewal analysis for sensible and latent heat flux density. Boundary-Layer Meteorology, 1996, 77, 249-266.

Spano D., Snyder R.L., Duce P., Paw U.K.T. Surface renewal analysis for sensible heat flux density using structure functions. Agricultural and Forest Meteorology, 1997, 86, 259-271.

Van Atta CW. Effect of coherent structures on structure functions of temperature in the atmospheric boundary layer. Arch. of Mech. 1977, 29, 161-171.

\section{SUMMARY}

Reliable estimation of surface sensible and latent heat flux is the most important process to appraise energy and mass exchange among atmosphere and biosphere. In this study the surface energy fluxes were measured over an irrigated orange orchard during 2005-2008 monitoring periods using a Surface Renewal-Energy Balance approach. The experimental area is located in a representative orchard growing area of eastern Sicily (Italy). The performance of Surface Renewal (SR) analysis for estimating sensible heat flux $(\mathrm{H})$ was analysed and evaluated in terms of correlation with $\mathrm{H}$ fluxes from the eddy covariance (EC) method.

Study revealed that the mean available energy $\left(\mathrm{R}_{\mathrm{N}^{-}}\right.$ $\mathrm{G}$ ) and latent heat flux (LE) were of about $300 \mathrm{~W} \mathrm{~m}^{-2}$ and $237 \mathrm{~W} \mathrm{~m}^{-2}$, respectively, during dry periods and unstable-case atmospheric conditions.

The estimated crop coefficient $\mathrm{K}_{\mathrm{c}}$ values for the orchard crop averaged close to 0.80 , which is considerably higher than previous FAO studies that found the value to be 0.65 for citrus with $70 \%$ of ground cover.

The intercepted photosynthetically active radiation (LI PAR) by the crop was measured and relationships between LAI and crop coefficient $\left(\mathrm{K}_{\mathrm{c}}\right)$ were established.

Keywords: Crop Coefficient, Crop Evapotranspiration, Surface Energy Fluxes, Surface Renewal. 
